BULLETIN Bulletin hispanique

HISPANIQUE Université Michel de Montaigne Bordeaux

115-1 | 2013

Poésie et société en Espagne : 1650-1750

\title{
Apollo polyglottus
}

Visión del plurilingüismo poético en la Metametrica (1663) de Juan

Caramuel

\section{Elvezio Canonica}

\section{(2) OpenEdition}

Journals

\section{Edición electrónica}

URL: http://journals.openedition.org/bulletinhispanique/2362

DOI: 10.4000/bulletinhispanique.2362

ISSN: 1775-3821

\section{Editor}

Presses universitaires de Bordeaux

\section{Edición impresa}

Fecha de publicación: 1 junio 2013

Paginación: 75-95

ISBN: 978-2-86781-898-1

ISSN: 0007-4640

Referencia electrónica

Elvezio Canonica, « Apollo polyglottus », Bulletin hispanique [En línea], 115-1 | 2013, Publicado el 01 junio 2016, consultado el 03 mayo 2019. URL : http://journals.openedition.org/bulletinhispanique/2362 ;

DOI : 10.4000/bulletinhispanique.2362 


\title{
Apollo polyglottus. Visión del plurilingüismo poético en la Metametrica (1663) de Juan Caramuel
}

\author{
Elvezio Canonica \\ Université Michel de Montaigne - Bordeaux 3
}

Cette contribution se propose de faire connaître une parcelle minime de l'immense ceuvre de Juan Caramuel, la Metametrica (1663). Nous nous concentrons, notamment, sur un traité de l'ceuvre dans lequel le polygraphe madrilène présente sa vision de l'écriture poétique bi-et plurilingue qui se base à la fois sur l'ars combinatoria médiévale, comme reflet $d u$ dynamisme changeant de la Création et sur la tradition biblique de la confusio linguarum babélique et de son rachat à la Pentecôte.

Mots-clés: Caramuel, plurilinguisme poétique, ars combinatoria, Babel, Pentecôte.

Esta contribución se propone dar a conocer una minima parcela de la inmensa obra de Juan Caramuel, la Metametrica (1663). En particular, nos concentramos en un tratado de la obra en el que el polígrafo madrileño presenta su peculiar visión de la escritura poética bi-y plurilingüe que se funda tanto en la ars combinatoria medieval, en tanto expresión del dinamismo proteico de la Creación, como en la tradición biblica de la confusio linguarum babélica y de su rescate en Pentecostés.

Palabras clave: Caramuel, plurlingüismo poético, ars combinatoria, Babel, Pentecostés.

This contribution aims at making known a minimal particle of Juan Caramuel's immense work, la Metametrica (1663). We concentrate upon a book's treatise, in which the polygraph from Madrid presents his views on poetical bi-and multi-lingual writing, based at the same time on the medieval ars combinatorial, as on the reflection of the changing dynamism of the Creation, of the biblical tradition of Babel's "confusio linguarum", and its redeeming on Whitsun.

Keywords: Caramuel, poetical multilingualism, ars combinatorial, Babel, Whitsun. 


\section{INTRODUCCIÓN}

\section{I.1 Caramuel y la Metametrica}

Sin duda el más extraordinario -y probablemente también el más estrafalariode los tratados métricos que se publicaron en la segunda mitad del siglo XVII es la obra del monje cisterciense madrileño Juan Caramuel y Lobkowitz. Dicha obra, que su autor tituló: Primus calamus, se publicó entre 1663 y 1668, en dos libros: la Metametrica (Roma, 1663) y la Rythmica (Sant'Angelo le Fratte, 1665-1668). De hecho, en el proyecto inicial de Caramuel, tal y como lo da a conocer en la Rythmica, había también un tercer libro, que tendría que haber ocupado el primer lugar de la trilogía, titulado: «Grammatica», que no llegó a publicarse. Nicolás Antonio, el famoso bibliógrafo sevillano, contemporáneo de Caramuel, en su Bibliotheca Hispana Nova afirma que este libro proyectado hubiera tenido que contener las materias siguientes: "Artem Grammaticam linguarum Latina, Graeca, Hispania, Hebra, Graco-Latina, Syriacam, HispanoArabicam, Megriliensem, Sinensem \& c.»', lo cual es ya una buena muestra del extraordinario don de lenguas del que gozaba Caramuel. Apreciamos también la progresión que suponía el proyecto inicial, en el que la Metametrica sería el tercer libro, como el último paso en un camino de dificultad creciente. Es por otra parte lo que el mismo autor afirma a propósito de esta tercera parte de su obra magna: "Artem hanc, quam veteres Musae non docent, quam nescit antiquus Parnassus, ultra Parnassus, \& Scientiam Metricam reperi, \& ideo Metametricam vocari volui, \& quia est ditissima, \& copiosissima, per ulteriora tempe distributam Apollinibus diversis consecrari» (cit. apud Isabel Paraíso, ed. cit., p. 10). Se trata, dicho de otro modo, de mostrar lo que el antiguo Parnaso desconoce («nescit») y de explorar un campo nuevo y virgen de la ciencia métrica. Apreciamos, además de cierta presunción, el afán modernista del polígrafo madrileño, que parece anunciar el espíritu del Siglo de la Luces. De hecho, la novedad que propone Caramuel puede apreciarse leyendo atentamente el título completo de su Metametrica, que reza: Ioannis Caramuelis Primus calamus ob oculos ponens metametricam que variis currentium, recurrentium, adscendentium, descendentium, nec non circumvolantium versuum ductibus, aut cri incisos, aut buxo insculptos aut plumbo infusos multiformes labyrinthos exornat ${ }^{2}$. En otras palabras, lo que se propone explorar Caramuel es lo que podríamos denominar la "poesía artificiosa» ${ }^{3}$. Isabel Paraíso, la autora de la primera edición moderna

1. Cf. Nicolás Antonio, Bibliotheca Hispana Nova, t. I, Madrid, F.U.E, 1999. Sobre las ideas gramaticales de Caramuel, véase la edición y traducción de su tratado Praecursor Logicus: Complectens Grammaticam Audacem (ed. facs. Stuttgart-Bad Cannastatt, 1989), llevada a cabo por P. Arias (Gramática audaz, Pamplona, Eunsa, 2000).

2. Romae, Fabius Falconius excudebat Anno MDCLXIII, Superiorum Consensu. Citamos directamente de la edición original, microfilmada en la Biblioteca Nacional de Madrid (signatura R 55).

3. Cf. Giovanni Pozzi, Poesia per gioco. Prontuario di figure artificiose, Bologna, IL Mulino, 1984. 
de la Rythmica, en traducción castellana, (mientras que la Metametrica sigue inédita) afirma acertadamente que "parafraseando a Gracián - autor que Caramuel cita y emplea - podríamos decir que la "agudeza y arte de ingenio" para la Métrica encuentra su culminación en la Metametrica del obispo madrileño» ${ }^{4}$. Si en la Rythmica, Caramuel «se centrará en la versificación de las lenguas modernas, especialmente la española, de la cual hará un tratamiento exhaustivo», en la Metametrica "encontramos, además de la inicial gramática comparada, una métrica renacentista-barroca en lengua latina y con enfoque también comparado (tomando como referencia fundamental la de origen español e italiano, pero abarcando igualmente otros orígenes: hebreo, francés, neerlandés, etc., todo ello en pinceladas) ${ }^{5}$. Se trata, por tanto, también de un ensanchamiento de la perspectiva, que pasa del estudio de la versificación española (en la Rythmica) al de las distintas tradiciones poéticas, en sus lenguas respectivas (en la Metametrica).

No es de extrañar que esta obra no haya tenido la difusión que se merece, ya que una serie de factores que tienen que ver con su estructura, compleja y bastante singular y confusa, y también con la historia agitada de su publicación complicaron notablemente su conocimiento y difusión. En efecto, la obra de 1663 fue publicada en cinco tipografías distintas, lo cual conllevó un acusado desorden en la paginación. Apareció en dos volúmenes, por un total de 835 folios, que sin embargo no están numerados normalmente, sino por cuadernillos de numeración independiente. También la división de la materia es algo caótica, y acude a una terminología fantástica, que llama los libros «Apolos», los capítulos «Musas», divididas éstas con epítetos a veces puramente metafóricos ${ }^{6}$. Esta obra representa, en suma, dentro de la ecléctica y fértil producción caramueliana, un eslabón importante para comprender una de sus vertientes, quizás la que más le preocupó, la de la ars combinatoria. En la obra, en efecto, se teoriza la posibilidad de aplicar a la producción poética una serie de reglas matemáticas afín de desvelar las estructuras rítmicas, las sucesiones fónicas, los esquemas prosódicos abstractos, una suerte de "gramática generativa» de los textos versificados. Se trata del viaje de una mente visionaria y al mismo tiempo rigurosa, que pretende abarcarlo y al tiempo clasificarlo todo, al montar y desmontar los elementos constitutivos del código de la comunicación verbal, que es también el instrumento de la expresión poética. Se encuentran, por lo tanto, en su Metametrica, al lado de enteros tratados, suyos y de otros autores, un rápido vademécum gramatical de la lengua latina, de la hebrea, léxicos de desinencias y de rimas, distinciones sutiles acerca de los pies en la métrica, análisis rítmicos, excursiones en el campo de la poesía bi- y plurilingüe (que será el objeto de la presente comunicación), secciones dedicadas a las figuras

4. Primer cálamo de Juan Caramuel, Tomo II. Rítmica, ed. Isabel Paraíso, Universidad de Valladolid, 2007 p. 10.

5. Ibid.

6. Nos remitimos para esta descripción al ensayo de Giovanni Pozzi, La parola dipinta, Milano, Adelphi, 1981, pp. 243-244. 
retóricas, a la poesía visual, que es quizás la parte mas fascinante de la obra: acrósticos, anagramas, palíndromos, composiciones a base de permutaciones de letras, todo ello acompañado por estupendas reproducciones ${ }^{7}$.

Imponente es el aparato de citas, que demuestra una erudición absolutamente extraordinaria: en este corpus, destacan los autores clásicos griegos y latinos, pero también las auctoritates italianas y españolas, de acuerdo con la concepción comparatista que es el fundamento de sus análisis. Se nota la repetición de unas cuantas autoridades, bastante trilladas por lo demás, como la de Virgilio, Ovidio y Horacio para los latinos; los italianos más frecuentemente citados son el inevitable Petrarca, con alguna breve aparición de los contemporáneos Marino y Anguillara (el traductor italiano de las Metamorfosis de Ovidio). En cuanto a los autores hispanos, es aplastante la presencia de Góngora, al lado de la más sorprendente obra del Príncipe de Esquilache, Francisco de Borja y Aragón, nieto de San Francisco de Borja, también frecuentemente citada y de signo opuesto al culteranismo gongorino, como es bien sabido.

\section{I.2 Datos biográficos}

Pero antes de entrar en el análisis precisamente de uno de estos libros, el llamado por el autor Apollus polyglottus, nos parece necesario dar cuenta brevemente de la biografía de su autor, tan extraordinaria y agitada como su obra. Ya don Marcelino Menéndez Pelayo, en su Historia de las ideas estéticas, afirmaba hablando de él que es «el más erudito y fecundo de los polígrafos del siglo XVII» ${ }^{8}$ y Díez Echarri afirma que Caramuel es «el más destacado, el más completo y acaso el menos leído de nuestros tratadistas métricos del Siglo de Oro"". Nació Caramuel en Madrid en 1606, hijo de un ingeniero natural de Luxemburgo y de una noble dama procedente de Bohemia, como el mismo Caramuel recordará en una carta de 1645: «Matre Bohema et patre Lutzemburgensis natum». Su primera formación universitaria es enteramente española, y se lleva a cabo en la Universidad de Alcalá de Henares, en artes y filosofía. Su compañero de estudios es el futuro escritor y teólogo jesuita Juan Eugenio Nieremberg. Pasa luego a la Universidad de Salamanca para cursar los estudios de teología y en 1632 Caramuel viaja a Lovaina, donde profundiza las ciencias naturales y la política, y donde escribe su primer texto de metafísica, que se caracteriza por una gran libertad con respecto a las corrientes escolásticas por entonces dominantes. Desde su llegada a Flandes tiene que ocuparse también

7. Víctor Infantes publicó una selección de los Laberintos (Madrid, Visor, 1981). Otros poemas figurados se pueden contemplar en el ya citado libro del p. Giovanni Pozzi, La parola dipinta, passim. Sobre la poesía visual de Caramuel, véase también el artículo de Giuseppe Grilli, "Poesia artificiosa e metametrica nella letteratura catalana», Annali dell'Istituto Universtiario orientale. Sezione romanza, 1985, XXVII, 2, Napoli, pp. 293-355 (en part. pp. 310-315).

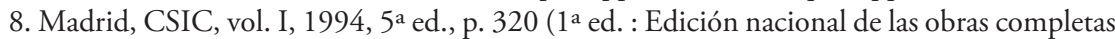
de Menéndez Pelayo. Vol. 2, Madrid, Consejo Superior de Investigaciones Científicas, 1940).

9. Teorías métricas del Siglo de Oro, Madrid, CSIC, 1949, p. 87. 
de trabajos prácticos, como la fortificación de la ciudad, amenazada por holandeses y franceses. En Flandes es donde también toma cartas en el asunto del problema teológico de la gracia, sosteniendo la teoría del probabilismo, lo cual le atrajo la oposición de Pascal y de los jansenistas. Debido a sus posturas algo heterodoxas, no puede medrar en Lovaina y emprende un vagabundeo por media Europa, frecuentando los círculos de los religiosos cosmopolitas, acomunados por una sed de conocimiento, por el empleo del latín y por la común formación teológica. Estos hacían de su enciclopedismo un arte y un oficio. En el caso de Caramuel, su preparación en lógica y en matemática se hermanó pronto con un anhelo por crear una nueva ars combinatoria en la tradición luliana y anunciando a Leibniz, que se traduce en la creación de un lenguaje simbólico que pueda permitir la comunicación entre los distintos campos del saber, así como entre las distintas tradiciones culturales y entre idiomas diversos. En 1647 lo encontramos en Praga, donde se dedica al estudio de las lenguas orientales y a la composición de obras teológicas y filosóficas, que permanecen en gran parte inéditas. En 1654, la elección de su amigo Fabio Chigi al solio pontifical, con el nombre de Alejandro VII le atrae a Italia, en la perspectiva de conseguir un capelo cardenalicio, o por lo menos un obispado. Sólo conseguirá lo segundo, dos ańos más tarde, en 1656, y en una sede de poco brillo como era la de Campagna, en las cercanías de Salerno. Algunos años más tarde conseguirá ser nombrado en otra sede, un poco más atractiva sin dejar de ser modesta, la de Vigevano, en el Milanesado. Aquí, ya casi al final de su trayectoria vital, dejará aún señales de su ciencia, esbozando las líneas arquitectónicas de la teatral fachada del «duomo» de esta ciudad. Es aquí donde fallecerá en 1682, a la respetable edad de 76 años.

\section{El libro llamado Apollo Polyglottus}

Este libro se abre con una breve introducción en dos partes: una en verso y la otra en prosa, donde Caramuel pondera las virtudes de la composición poética en varias lenguas. Los cuatro versos son los siguientes:
A nulla noster lingua dependet Apollo:
Ut methodum expendat, non tamen una satis
ecce tacendo loqui solet, \& felicior uti
audebit linguis pluribus ipse simul ${ }^{10}$.

El breve capitulillo en prosa dice lo siguiente:

Ditissimus est Apollo multilinguis, que enim in uno conficiuntur idiomate, possunt etiam in alio: possunt simul aut successive in multis. Sunt illi tributarij alij Apollines, quorum ipse opibus \& thesauris instruitur. Et ideo illum in hunc locum remisi, ut possem superius dicta breviter recognoscere, \& ad usum reducere.

10. «Nuestro Apolo no depende de ninguna lengua: / sin embargo, para desplegar su método, / no suele contentarse con una / y he aquí que suele hablar callando, / y con mayor felicidad / se atreverá a hablar en lenguas distintas al mismo tiempo». (traducción nuestra) 
Sane tametsi multarum linguarum possit esse consideratio, duabus solent esse contenti, qui his mysteriis student. Duabus inquam, non determinatis, sed indeterminatis. Bilinguis igitur dici noster Apollo poterit: quod duabus utatur, cum suum communicat Philomusis influxum ${ }^{11}$.

De estos dos preámbulos podemos sacar en claro dos cosas: ante todo, que la reflexión de Caramuel sobre el plurilingüismo poético no puede disociarse de su condición de eclesiástico y, por tanto, está marcada por un fondo bíblico y teológico, en particular por el episodio del don de lenguas en Pentecostés, y al cual va a dedicar uno de sus primeros capítulos, llamado «Musa eloquens»; por el otro lado, anuncia claramente que se va a limitar al bilingüismo poético, con una argumentación algo intrincada y un poco sofista, puesto que es evidente que esta reducción le va a facilitar notablemente la tarea, al excluir los ejemplos de poesía plurilingüe, o políglota, como en cambio lo anuncia desde el título del libro.

Se compone este libro de trece capítulos, llamados Musas, cada una acompańada por el epíteto que la define. Son las siguientes:

\author{
MUSA I. CHARACTERICA (DXCIII) (593) \\ MUSA II. ELOQUENS (594) \\ MUSA III. BILINGUIS SUCCESSIVA (595-598) \\ MUSA IV. BILINGUIS SIMULTANEA (599) \\ MUSA V. ANAGRAMMATICA (600) \\ MUSA VI. ACROSTICHA (601) \\ MUSA VII. PAROMOEA (602) \\ MUSA VIII. GLOSSOGRAPHA (603) \\ MUSA IX. ECHETICA (604) \\ MUSA X. PARODICA (605) \\ MUSA XI. PEREGRINA (606) \\ MUSA XII. BELGICA (607) \\ MUSA XIII. GERMANICA (608-610)
}

Si consideramos el conjunto de los trece capítulos nos damos cuenta de que la noción de "poliglotismo poético» subyacente es bastante particular. De hecho, como veremos a continuación, el tratamiento del plurilingüismo poético se concentra en la tercera y en la cuarta musas. En la tercera, se toman en consideración las composiciones poéticas en las que el fragmento alóglota se inserta en una frase o verso en la lengua principal (español, italiano, latín), un procedimiento que se define como «bilingüismo sucesivo»; en la cuarta musa,

11. Es Apolo multilingüe muy rico, ya que, las cosas que se agotan en un solo idioma pueden expresarse, de manera simultánea o sucesiva, en muchos. De ello son tributarios los otros Apolos, cuyas riquezas y tesoros sirven para construirle a él mismo. Y es por ello por lo que yo he querido ponerlo en este lugar, para que pueda reconocerse más rápidamente lo que diría de manera superior y para que pueda utilizarse. Desde luego, también podrían tomarse en consideración muchas lenguas, sin embargo los que estudian estos misterios, suelen contentarse con dos. Digo dos, no determinadas, sino indeterminadas. De hecho, nuestro Apolo podría llamarse «bilingüe»: porque emplearía dos lenguas cuando comunica su influencia a los que están enamorados de las musas (traducción nuestra). 
el fenómeno de la escritura bilingüe se considera en su variante «simultánea», es decir en aquellas composiciones que pueden leerse al mismo tiempo en dos lenguas distintas (generalmente, el latín y el español y/o el italiano). Sin embargo, en las otras «musas» también se da cabida a cierto grado de poliglotismo poético, aunque éste se combina con algún recurso artificioso: el anagrama, el acróstico, el eco, etc. Volvemos a encontrar, en estos casos, la inclinación más propia de Caramuel, la de la ars combinatoria, como se ha visto. Y de hecho, podemos afirmar que su concepción de la escritura poética bi- o plurilingüe forma parte de su atracción por el dinamismo proteico de la Creación, de la cual el poliglotismo poético no es sino una variable dentro del campo de las infinitas combinaciones posibles que pueden obtenerse manejando la materia lingüística. Ello explica también que su tratadillo sobre la poesía plurilingüe diste mucho de ser exhaustivo, y los ejemplos que trae a colación son por lo general harto conocidos y tópicos.

Vamos a presentar a continuación las trece musas que componen el libro. Nos vamos a detener con más detalle con las que más tienen que ver con el tema de la escritura poética bi- o plurilingüe, sin dejar por ello de tratar más brevemente de las otras.

\section{Las Musas}

\section{III.1 Musa characterica}

La primera musa, llamada «characterica» se refiere a los caracteres tipográficos de los distintos alfabetos, que pueden interferir en la lengua vehicular para crear palabras nuevas. Los ejemplos que proporciona se refieren a dos letras del alfabeto griego, la «rho» ( $\rho$ ) y la «nu» (v) que pueden confundirse, por su forma, con las latinas "p» $\mathrm{y}$ «v», lo cual puede dar lugar a la creación de dobletes, como en el caso de veprvvos, que puede leerse tanto como «Neptunus» o bien como «Vertunus», que eran dos divinidades de los romanos (n. 1). No deja de ser curioso el comentario que Caramuel extrae de una de estas permutaciones: se trata del sustantivo griego $\alpha \rho \tau$ ç, el pan, que leído a la latina da: «aptus». Y Caramuel comenta: «est enim aptissimus cibus» ${ }^{12}$ (n. 2). También en un par de casos intervienen otras lenguas modernas, como el italiano y el español. En italiano, consigue Caramuel componer un endecasílabo a partir de una serie de letras del alfabeto griego, que hay que pronunciar por separado: «Ne la $\phi . \delta . \phi$. v. $\rho$. la $\beta$ », lo cual da en italiano el endecasílabo: «Ne la fideltà [sic] finirò la vita» (n. 3), haciendo ciertas concesiones, sin embargo, ya que la letra $\phi$ se lee «fe» en lugar de "phi», la $v$ se lee «ni» (en lugar de "nu») y la $\beta$ se convierte en "vita» en lugar de «beta». Sabemos que la pronunciación del griego en la época moderna procede de Erasmo. Por otra parte, la [e] y la [u] del griego han evolucionado en la [i], lo cual quizás puede explicar esta pronunciación, que sin embargo está

12. «Es la comida más conveniente». 
al servicio de un juego verbal. El verso así obtenido es la divisa de la familia Colomb, descendientes franceses de los «Colombo» del Piamonte ${ }^{13}$. Caramuel cita otros juegos similares con la lengua española: un verso endecasílabo que se termina con una pregunta, y cuya respuesta se encuentra, en forma de eco, en las dos letras griegas que siguen: «A dò navega el mercader avaro? $\alpha . \rho$., o sea «al faro» («alfa» $\mathrm{y}$ «rho»); (n. 4) o bien, la lectura de las dos letras griegas $\chi \& \rho$, que dan «chi \& Rho» es decir el verbo español: «quiero». (n. 5)

\section{III.2 Musa eloquens}

Pasamos a la segunda musa, que es llamada «eloquens», cuya pertinencia en este libro es sobre todo de tipo ideológico, puesto que consiste en la reproducción, acompañada de algunos comentarios, del episodio de Pentecostés contenido en el libro de los Hechos de los Apóstoles (2, 1-13), que Caramuel cita según el texto de la Vulgata. Como se recordará, los discípulos reunidos después de la muerte y la resurrección de Jesucristo reciben el don del Espíritu Santo en forma de lenguas de fuego que bajan del cielo hasta detenerse encima de sus cabezas. Es así como reciben el don de lenguas, es decir que de repente hablan cada uno en una lengua distinta («coeperunt loqui variis linguis, prout Spiritus sanctus dabat eloqui illis», 2,4). Tenemos por tanto un plurilingüismo sucesivo. Pero resulta que, a pesar de la gran diversidad de lenguas, los moradores de Jerusalén, que provenían de todas las naciones («ex omni natione, que sub calo est», 2,5) comprendían cada uno, individualmente, lo que los discípulos les decían ( facta autem hac voce, convenit multitudo et confusa est, quoniam audiebat unusquisque lingua sua illos loquentes», 2,6), lo cual fue causa de gran estupor «Stupebant autem et mirabantur dicentes: 'Nonne ecce omnes isti, qui loquuntur, Galilai sunt? Et quomodo nos audimus unusquisque, propia lingua nostra in qua nati sumus? (citamos de la edición Nestlé-Aland, Novum Testamentum Graece et Latinae, Deutsche Bibelgesellschaft, Stuttgart, 1984)». Tenemos aquí el plurilingüismo simultáneo, símbolo de la unidad en la diversidad. De esta manera es cómo Caramuel introduce los dos capítulos siguientes, en los que va a presentar estas dos modalidades de plurilingüismo, que define previamente de esta manera:

\footnotetext{
Oratio multilinguis est duplex: successiva vidilicet simultanea. Successiva unam periodum ex una lingua, \& alteram sumit ex altera. Simultanea uno \& eodem verborum contextu loquitur diversis linguis. Opus est hanc divisionem dilucidare, \& exemplis firmare: ut possimus Apostolos loquentes varijs linguis audire: nam, \& ipsi successive, \& sapissime simul, linguis diversis loquebantur ${ }^{14}$.
}

13. "Devise de la famille Colomb (région de Trièves, Isère, Alpes françaises. Tiercé en fasce de gueules, d'argent et de sable, l'argent chargé de 3 colombes d'azur. Devise: En fedeltà finiro la vita.); En (in) fidélité à la vie que je vais Colombo (Piémont) » [Page consultée le 3 avril 2013]. Disponibilité et accès http://encyclo.voila.fr/wiki/Armorial_du_Trièves

14. "La oración multilingüe es doble : sucesiva o bien simultánea. Sucesiva es cuando un periodo está en una lengua, y el otro adopta otra lengua. Simultánea es cuando una misma palabra está compuesta de diversas lenguas. Es preciso aclarar esta división, y afirmarla con 


\section{III.3 Musa bilinguis successiva}

La tercera musa, "bilinguis successiva» se concentra pues en la primera modalidad del plurilingüismo que acaba de definir. Se trata de un capítulo bastante amplio, dividido a su vez en una serie de apartados, que van numerados (del 595 al 598). Aparece también, separado como un capítulo aparte, un apartado titulado "De versibus polyglottis», que sin embargo no sigue la numeración de los otros (es el n. MXCVII : 1097), como si su colocación en este lugar fuese posterior. Se abre esta "Musa» con una alusión a unas octavas reales bilingües que el propio Caramuel afirma haber escuchado («audivi») en el ańo 1616. No cita ni los textos ni los autores, y no indica en cuáles lenguas, de manera que resulta difícil identificarlos. Está Caramuel convencido (y con esto abre el capítulo) que esta poesía bilingüe sucesiva es oriunda de Espańa ("Adulta \& nata est in Hispania»). Sin embargo, los primeros ejemplos que cita son de autores italianos: la famosa canción de Petrarca en la que inserta un verso de Arnaut Daniel (canc. V, estr.1), un verso de Ariosto en el que el poeta italiano cita un verso sacado de una Ecloga de Virgilio (Orlando furioso, 39, 60-Eclogae VI, 24). Se detiene a continuación a considerar una locución latina, que se había sustantivado y se encontraba en varias lenguas modernas: el «agnusdei», para indicar aquella reliquia hecha con la cera del cirio pascual y que toma la forma de un cordero, y que había sido bendecida y consagrada por el Papa ${ }^{15}$. Caramuel cita otra vez un verso de Ariosto ("Il Rè fece giurar su l'Agnus Dei». OF, 28, 40) ${ }^{16}$ y otro de Góngora, sacado de su romance, que hoy se considera de paternidad dudosa: «Recibí vuestro billete» ${ }^{17}$ : «Al fin mis atos se incluyen / en los que ciñen mi cuerpo, / y en un Agnus Dei de alchimia / se rematan mis corderos» (n. 6). Pasa luego a considerar otras locuciones latinas en boga, como "Non plus ultra», "Finis Terrae», «el hábito de Christus» (en referencia a la orden de caballería portuguesa). Para ilustrar estos casos, cita unos versos sacados de los Conceptos espirituales (1600) de Alonso de Ledesma. A continuación, tras recordar la opinión contraria a la mixtura de lenguas de

ejemplos, para que podamos oír a los Apóstoles hablar en varias lenguas: en efecto, ellos hablaron tanto de manera sucesiva como, y muy a menudo, de manera simultánea en diversas lenguas» (traducción nuestra).

15. «Agnus Dei, reliquia santa, que bendize el sumo Pontífice y consagra el primer año de su pontificado; y los demás que regularmente dizen ser de siete en siete años. Está a cargo del sacristán y de los capellanes disponer la cera; en la qual entra la de los cirios pascuales del año de antes, y con gran curiosidad, limpieza y reverencia y en diferentes moldes sacan los agnus de diferentes tamaños y de diversas figuras, en la una parte, y en la otra todos tienen el cordero, que da nombre a esta reliquia. Y presentados a su Santidad los bendize en la capilla y consagra con grandes ceremonias, echándolos en la vazías del agua que ha bendezido, derramando sobre ellas bálsamo y crisma, dize muchas oraciones» (S. de Covarrubias, Tesoro de la lengua castellana o española, Madrid, 1611, s.v.)

16. Cesare Segre, en su edición del poema, comenta este verso de esta manera: «sull'ostia consacrata, come di deduce da 44, 8 - poi che giurato avea su l'ostia sacra-".

17. Forma parte de los atribuidos en Romances, ed. Antonio Carreño, Cátedra, Letras Hispánicas, n. 160, Madrid, 2000, 5e ed. revisada, p. 652. 
Cicerón, Caramuel trae a colación un fragmento de la décima sátira del libro primero de Horacio (vv. 20-33), en la cual se habla del poeta Lucillius Gaius, quien fue el creador del género satírico. Aquí también el juicio del poeta latino acerca de estos experimentos de bilingüismo poético es negativo, a pesar de la intervención de un interlocutor quien alaba la gracia y la belleza de estas mezclas, que compara con la de los vinos de Falerno y de $\mathrm{Chio}^{18}$. Pese a estos juicios negativos, Caramuel sigue defendiendo el poliglotismo poético, $\mathrm{y}$ nos proporciona otros ejemplos, sacados de la obra poética de Góngora. En particular, se detiene en un par de poemas que presentan unas palabras latinas, con la cuales el vate cordobés construye sendos juegos equívocos. El primero está sacado del romance "Murmuraban los rocines", vv. 106-109, en el que Góngora introduce un hemistiquio de la Eneida: «tendimus in Latium» («nos dirigimos a Lacio», I, 204-206), del cual lleva a cabo una traducción jocosa: (n. 7)

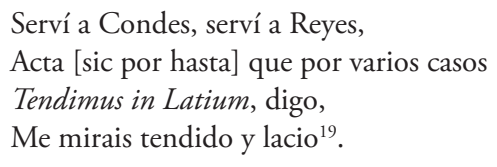

El segundo, de otro romance: «¿Quién es aquel caballero», vv. 25-28 ${ }^{20}$, en una "frase que asocia el famoso dicho de Julio César «veni, vidi, vici» con la moneda por paronomasia, el maravedí», como indica Antonio Carreño: (n. 8)

Toda la tierra e corrido,
El mar e visto en Latin,
Mare-vidi muchas vezes,
Pero no un maravedí.

Finalmente, termina con un ejemplo que, en todo rigor, pertenecería a la modalidad de bilingüismo simultáneo. Se trata de unos versos en español, donde sin embargo, a modo de eufemismo, está escondida una palabra latina traducida: (n. 9)

Hizo ayer su confession

Un Marido, y dixo enfin,

Quo[sic] él era lo que en Latín,

Es desnudo el coroçon.

18. "At magnum fecit, quod verbis Greca Latinis

miscuit.' O seri studiorum, quine putetis

difficile et mirum, Rhodio quod Pitholeonti

contigit? 'At sermo lingua concinnus utraque

suavio, ut Chio nota si conmixta Falerni est.»

- «iPor lo menos, apreciáis lo que hizo [Lucilio], el haber entreverado nuestra lengua latina de tantas palabras griegas ?» - Oh, estudiantes retrasados! ¿Es posible que vuestro saber pueda llegar hasta el extremo de admirar como una novedad unas proezas gramaticales dignas, como máximo, de un Pitoleón de Rodas? - Sin embargo, esta mezcla de las dos lenguas es muy suave, como cuando se mezcla el vino de Chio con un Falerno afamado» (traducción personal).

19. Romance "Murmuraban los rocines », vv. 106-109.

20. Ed. Carreño cit. p. 377. 
El juego equívoco lo explica a continuación el propio Caramel con las siguientes palabras (que creo inútil traducir): (n.10): «Id quos Hispani desnudo coraçon vocant Latini Cor-nudum: \& maritos quos Cornutos Latini illos Hispani cornudos appellant».

El apartado más amplio de este libro es el que se titula «De versibus polyglottis». Empieza Caramuel recordando su época de estudiante en Alcalá, en 1620, donde:

erant in summo pretio carmina Latino-Hispanica, seu Hispano-Latina: illa nimirum, que alternative procedebant, \& carmina nostre lingue immiscebant Latinis. Audivi orationes Panegyricas hoc versuum genere: feci \& declamavi etiam.

Se refiere a la moda de la poesía hispano-latina, en el marco de las competencias entre las lenguas neolatinas, cuyo prestigio se medía por su mayor o menor proximidad a la lengua latina. El grado máximo de este bilingüismo simultáneo, claro está, se conseguía componiendo versos que pudieran leerse al mismo tiempo en la lengua moderna y en latín ${ }^{21}$. Sin embargo, en este capítulo, los ejemplos que Caramuel proporciona son más bien los que se refieren a casos de bilingüismo hispano-latino de carácter sucesivo. Cita un par de composiciones, que afirma haber compuesto él mismo en su juventud. El primer ejemplo (n. 11) es el de una lira-sextina bilingüe (la estrofa utilizada por fray Luis de León para traducir las odas de Horacio) donde los versos castellanos son heptasílabos y los latinos tratados como si fueran endecasílabos: las dos rimas iniciales que alternan, por tanto son monolingües (las latinas son incluso rimas asonantes en o-a), mientras que la rima final, siendo un pareado, es bilingüe. A continuación, reproduce tres octavas bilingües, también de su cosecha, que son una descripción de la destrucción de Troya. Aquí también, las rimas alternantes de los seis primeros versos son monolingües, mientras que el pareado final presenta forzosamente una rima bilingüe. Todos los versos son endecasílabos, y los latinos se tratan según las reglas de versificación del español, aunque el porcentaje de sinalefas es muy bajo. Afirma luego Caramuel haber compuesto otros poemas en más lenguas ( «icut conformavimus hac Carmina, potuimus alia condere, que tribus, quatuor aut pluribus linguis corresponderent»), o sea en tres, cuatro o más lenguas. Pero no cita ninguno: en cambio, recuerda haber leído un soneto, que en latín llama "Epigramma», trilingüe, de Henrique Garcés, autor de origen portugués y que fue el primero en traducir el entero Canzoniere de Petrarca al castellano. En efecto, entre los poemas preliminares a su traducción, que apareció en Madrid en 1591, figuran dos sonetos de propuesta y respuesta, el primero del presentado fray Miguel de Montalvo, efectivamente trilingüe (latín-castellano-italiano), mientras que la respuesta, de Henrique Garcés, es un soneto cuatrilingüe (latín-castellano-italiano-portugués) ${ }^{22}$. En cambio,

21. Cf. Erasmo Buceta, "La tendencia a identificar el español con el latín», en Homenaje a R. Menéndez Pidal, t. I, Madrid, Hernando, 1925, pp. 85-108; Id. «De algunas composiciones hispano-latinas en el siglo XVII», en Revista de Filología Española, XIX, 1932, pp. 388-414.

22. Estos sonetos pueden leerse en la edición de la traducción de Garcés llevada a cabo por 
Caramuel cita el famoso soneto cuatrilingüe de Góngora, «Las tablas del bajel despedazadas», compuesto en castellano, latín, italiano y portugués, según la edición de Gonzalo de Hozes de 1633. Es curioso que sea el mismo Góngora el que le reprochará a Lope la composición de sonetos cuatrilingües (los dos que aparecen en sus Rimas de 1609 -n. 115 y n. 195), dirigiéndole un soneto de cabo roto que se termina con estos versos: «Y en cuatro lenguas no me escribas có- / que supuesto que escribes boberí- / lo vendrán a entender cuatro nació-». El último apartado se dedica enteramente a presentar unas composiciones bilingües italo-latinas compuestas con ocasión del fallecimiento de Fernando I, hermano menor de Carlos V, que fue emperador desde 1556 hasta su muerte en 1564. Caramuel reproduce una serie de cuatro sonetos, sin que quede claro quiénes son sus autores. Posiblemente los compuso él mismo. El primero, a diferencia de los otros casos ya encontrados, presenta verdaderos hexámetros latinos, que se combinan con los endecasílabos italianos, aunque el esquema métrico elegido excluye toda rima bilingüe ( $A B A B A B A B C D C D C D$, donde A y $\mathrm{C}$ son los versos italianos, $\mathrm{B}$ y $\mathrm{D}$ los latinos). El segundo es obra de una tal «Eleanora», posiblemente la hija del emperador recién fallecido, («Augusta suum solem») que vivía en Italia, pues estaba casada con el duque de Mantua Guglielmo Gonzaga. Presenta el mismo esquema métrico del precedente, pero empezando con el verso latino y con la añadidura de un estrambote de cinco heptasílabos italianos. El tercero es en todo idéntico al primero, mientras que el último va precedido de un interesante comentario:

\section{Austria postquam omnes Germanice lingue flavissas in lachrymas amaras vertaret: ut adhuc possit diutius \& dulcius lachrymari, ad Latine \& Italice Lingue purissimos thesauros recurrit, \& sicut binis oculis luget, sic duabus linguis gemit, thesaurumque sublatum a Parca deplorat.}

Se aprecia una oposición entre las lenguas germánicas, "amargas», y las lenguas latina e italiana, «dulces»; con las cuales además se puede llorar más tiempo («diutius»); además, es interesante la justificación del bilingüismo con respecto a la temática elegíaca: «así como se llora con los dos ojos, de la misma manera se gime en dos lenguas». Este cuarto y último soneto bilingüe presenta un cambio en el esquema métrico, en particular en la disposición de las rimas, que pasan de alternantes a abrazadas en los dos cuartetos (ABBAABBA / CDCDCD), pero sigue sin haber rimas bilingües.

\section{III.4 Musa bilinguis simultanea}

La Musa IV, llamada «Bilinguis simultanea», se compone casi exclusivamente de textos: cinco sonetos, que ilustran esta modalidad. Sin embargo, van

Justo García Morales, Madrid, Crisol, 1957, pp. 100-101. Sobre la traducción de Garcés, véase nuestro trabajo: «Il Canzoniere tradotto in spagnolo, nel Perù, dal minatore portoghese Henrique Garcés (1591)», P. Blanc (éd.), Dynamique d’une expansion culturelle. Pétrarque en Europe, XIVéXXe siècle, Paris, Champion, 2001, pp. 337-346. 
precedidos de un breve prólogo en el que Caramuel explica en qué consiste esta clase de bilingüismo simultáneo:

Plures linguas posse sibi succedere iam vidisti: at posse simul fluere \& in eodem verborum contextu reperiri impossibile aut saltem difficillimum iudicas. Et ego sicut impossibilia esse eiusmodi carmina nego esse diffcilia confiteor ${ }^{23}$.

De los cinco sonetos, cuatro van firmados, y uno de ellos es del propio Caramuel, mientras que otro tiene sólo las iniciales del nombre del autor (I.R.F.). Esta modalidad de bilingüismo simultáneo hispano-latino es bien conocida por los historiadores de la literatura y de la lengua, ya que se inscribe en el marco de la «defensa e ilustración» de las lenguas nacionales. Los mismos experimentos surgieron también en otras áreas lingüísticas que pretendían afirmar su mayor prestigio, demostrando su proximidad con la lengua latina, en particular Italia y Portugal. Se trata, de hecho, de manifestaciones de un nacionalismo lingüístico que hay que situar en el contexto del surgimiento de los estados nacionales, pero cuya calidad literaria no nos puede sino dejar muy perplejos. En efecto, para conseguir esta identificación entre el español y el latín, hace falta, ante todo, hacer caso omiso de todos los artículos, determinados e indeterminados, inexistentes en la lengua latina. El resultado es un texto que no es ni carne ni pescado, y que -cabe reconocerlo- hay que leer con muy buena voluntad. Los dos primeros sonetos, del p. Antonio Monroy, o.p. y del p. Tomás de San Vicencio, o.p. son sendos panegíricos de Felipe IV, en particular de su protección de las artes y de su política extranjera. Este soneto lo encuentra Caramuel en el Arte poética española de Díaz de Rengifo, publicada en 1592, en el capítulo que dedica al «soneto en dos lenguas» (cap. LI), acerca del cual Rengifo señalaba: «Bien es verdad que la escritura de la una y de la otra lengua son diferentes, pero basta que sea una, o casi una, la pronunciación». El mismo Caramuel indica su fuente: «Porrò apud Ioannem Rengifum in Arte Poetica». Puede deducirse, por lo tanto, que las iniciales I.R.F. aluden precisamente al nombre latinizado de Rengifo (Ioannes Rengifum).

Sigue a continuación el soneto «bilingüe simultáneo» del propio Caramuel sobre el cual nos vamos a concentrar con más detenimiento. Tratándose de su composición, el obispo madrileńo proporciona algunos datos acerca de la época de su composición, que resulta ser la de su primera juventud, o incluso de su infancia, cuando estudiaba en Alcalá («Hoc Epigramma iuvenis, aut verius puer, concinnavi compluti, ut ingenium excolerem»). Además, va acompañado por unas notas explicativas a pie de página, que resuelven potenciales dudas acerca de ciertas palabras que utiliza, y también acerca de esta técnica poética tan peculiar. Es así como, por ejemplo, justifica la grafía del adverbio «digna mente», en dos palabras: «Apud Latinos est duplex vox, \& significat cantare

23. «Ya has visto cómo pueden varias lenguas alternarse; pero que también puedan fluir simultáneamente y estar contenidas en unas mismas palabras juzgarás por cosa imposible, o por lo menos, muy difícil de conseguir. Y yo me niego a considerar los poemas de esta clase imposibles, aunque confieso que son difíciles» (traducción personal). 
mente digna: apud Hispanos est adverbium, digne». Como sabemos, en efecto, la formación de los adverbios en "-mente» procede del latín de la Iglesia, puesto que indicaba la manera con la cual la «mente» debía efectuar su acción: por ejemplo, "devotamente», significó al principio "con mente devota», etc. A partir de ahí, se generalizó su uso. Otra nota pretende aclarar la diferencia de acentuación que, a pesar de la misma grafía, hay que suponer en la doble lectura. Se refiere al verbo "resuscita», del cual dice Caramuel: «in penultima aut in antepenultima accentum habet. Resuscita, Latinum est: sed Resuscita, Hispanicum». Otras dos notas merecen considerarse, porque permiten no sólo comprender la técnica, sino también la relación de Caramuel con el lenguaje, siempre fundada en el ars combinatoria. En dos casos utiliza el sintagma «de los», en el v. 9: «Contempla de-los triunfos glorias tantas» y en el v. 12: «Delos Filippos generosos cantas». Ahora bien: en la nota correspondiente, el autor explica que: "Delos Latine est simplex vox, notatque celebrem Insulam Musis \& Apollini sacra m.: Hispanice est dúplex vox de los». O sea que nos explica que ha echado mano de la figura del calambur bilingüe, lo cual permite una doble lectura, una referida a la famosa isla (en latín) y otra como la sucesión de la preposición «de» y del artículo plural «los» (en castellano). Lo mismo ocurre con el sintagma «de oi» que aparece en el v. 11: «De oi excedant maritimas arenas». En nota leemos lo siguiente: "De oi, aut de oy, Hispanice ab hodierna die: Latine D'Eoi, hoc est Dij Eoi», o sea «los dioses de Oriente», considerando que «Eoi» es el plural del adjetivo latino "Eous, a um», un calco del griego $\rceil \omega 0 \varsigma$ $\varepsilon \omega \circ \varsigma$ («de oriente, oriental»). Es bastante asombroso el cuidado con el que Caramuel construye su poema, no contentándose con componer un soneto bilingüe simultáneo, sino añadiendo también unos juegos fónicos bilingües que permiten una doble lectura.

El último soneto es de contenido devoto, obra del p. Federico Enríquez, del monasterio de los jerónimos «apud Palatium qui dicitur El buen retiro». Es decir, pues, que nos situamos después de la tercera década del siglo XVII, cuando se terminó la construcción de dicho palacio, en las tierras que el condeduque de Olivares cedió al rey Felipe IV para su edificación.

Pasamos ahora a considerar más brevemente las otras musas, deteniéndonos en los aspectos que más tienen que ver con el plurilingüismo poético.

\section{III.5 Musa anagrammatica}

La musa quinta, llamada "anagrammatica», se funda en la creación de nuevas palabras a partir de un "programma", o sea un verso de base a partir del cual se crean las variaciones por anagramas. Estas se componen en una lengua diferente de la del «programma»: un ejemplo nos permite situar la época de composición de este capítulo, puesto que el «programma» consiste en el nombre completo del recién nacido hijo de Felipe IV, en 1626, el malogrado príncipe Baltasar Carlos: "Balthasar Carolus Dominicus Lucas», que se convierte en el español: «De la lis y rubí nascí Catholica Rosa». Este anagrama aparece, junto a otros, en un certamen organizado por la Universidad de Salamanca que se 
publicó en 1630 por los tipos de Cristóbal de la Zarraga (son todos datos que nos proporciona Caramuel). La fecha de publicación tiene que ver con el ejercicio poético propuesto, ya que el «progamma» latino contiene precisamente treinta letras, para «exprimere annum, quo in academia Palestra de ingenio \& acumine decertabatum. Se trataba pues de encontrar un anagrama en el cual se volviesen a encontrar las treinta letras, pero en otra lengua, el español este caso. Notamos, sin embargo, que a pesar de respetar el número de las letras, el autor del anagrama utiliza la vocal «e» en «De», ausente del «programma» latino; además, no volvemos a encontrar todas las vocales (p. ej. las tres «ues», etc.). De hecho, Caramuel se da cuenta de estas incongruencias: «interim purum non est, sed multum a legibus prescriptis errans; nam SUUM vertit in EIYI: \& ómnium opinione quatuor in Anagrammate mutare litteris, nimium \& intolerabile est». Pero en la presentación de este anagrama, comprendemos mejor el porqué de su éxito, que tiene que ver con el hecho de estar compuesto en español, entre los numerosos ejemplos latinos: "Ex illo multa dedit Idioma Latinum Anagrammata: sed hoc quia erat Hispanicum visum fuit laude dignius" (subrayado nuestro).

\section{III.6 Musa acrosticha}

La musa siguiente es la llamada "Acrosticha», y ofrece un solo ejemplo, aunque muy elaborado, en el que el recurso artificioso del acróstico, bien conocido por lo menos desde los versos preliminares de La Celestina de 1501, produce un texto de doble lectura, como es habitual en los poemas acrósticos, pero además, en dos lenguas, ya que el poema está en latín y el acróstico en castellano. Se trata además de un acróstico compuesto, es decir que no son sólo las primeras letras de cada verso las que van a formar el mensaje oculto, sino también las que se sitúan al principio de cada hemistiquio del verso latino, que se divide en tres partes. Además, y por si fuera poco, la lectura correcta se realiza juntando no directamente las primeras letras, sino alternando las de los versos impares con las de los versos pares, en las dos primeras columnas. Sin embargo, no me atrevo a juzgar de la corrección de estos versos latinos, por ser incompetente en ello, pero da la impresión de que se trata de versos bastantes artificiales y que sirven ante todo a posibilitar la lectura vertical, que produce la frase española: «Francia, tu Lis fruto dio», una frase que el propio Caramuel traduce en latín y explica de la siguiente manera: «Gallia tuum Lilium (nimirum, -"naturalmente" - Isabella Borbonia, Henrici IV filia \& Ludovici XIII Galliarum Regum soror) fructum dedit». Se trata, evidentemente, otra vez de celebrar el nacimiento del infante Baltasar Carlos en 1629.

\section{III.7 Musa paromoea}

La musa siguiente, la séptima, es la musa «paromoea», y puede considerarse una variante del acróstico, donde sin embargo no son sólo las primeras letras de cada verso, sino las de cada palabra de cada verso las que se toman en 
consideración. Aquí también la doble lectura supone el bilingüismo. Un caso interesante se da en un verso latino que produce un verbo griego: «Lais, Eros, \& Ithis, Chiron, \& Eros, Iris altern. Al juntar las primeras letras de cada palabras, $\mathrm{y}$ al transponerlas al alfabeto griego, se obtiene el verbo: $\lambda \varepsilon \chi \varepsilon 1$, que significa «lamer», y que Caramuel explica, curiosamente, a través del francés: «Gallice, ii lesche: Latine, lambit». Es evidentemente, una sátira oculta de los aduladores los cuales, nos dice Caramuel, «ut mordeant, lambunt» («para poder morder, o sea comer, lamen, o sea adulan»). Interesante este último ejemplo también para la historia de la lengua española, en particular para la pronunciación de la fricativa gutural $/ \mathrm{x} /$, que aun tenía una realización palatal, como lo muestra el paso del griego $\lambda \varepsilon \chi \varepsilon 1$ al francés lesche. Ello confirma la composición mucho más temprana de este libro con respecto a la fecha de su impresión, 1663, una época en la que este fonema ya se pronunciaba fricativo gutural, o sea como la actual «jota». Además, este ejemplo es otra muestra de una pronunciación castellanizada del griego, ya que el fonema griego $|\chi|$, en griego clásico se pronuncia de manera gutural o gutural-fricativa, pero nunca palatal. Otros ejemplos de esta musa tienen que ver con el mundo militar, ya que la lectura oculta, que se realiza a través de este peculiar recurso, puede permitir la transmisión de un mensaje cifrado en castellano al juntar todas las primeras letras del mensaje oficial en latín. Otra modalidad consiste en la permutación de las palabras del mensaje oficial, de manera que la respuesta, siempre en latín, le permite a su receptor descifrar un mensaje secreto, que puede decidir del éxito de una batalla, por ejemplo: «exivit Regis Patruus: nos Didacum Alvaradum exspectare debemus. Exterminat Dantiscum pestis. Obijt rex». En la respuesta, echando mano de la musa "paromoea» se puede dar una orden que puede ser de importancia: «Patruus Regis exivit: nos debemus exspectare Didacum Alvaradum: pestis exterminat Dantiscum. Rex obijt», lo cual da el siguiente mensaje: «Prended a Pedro».

\section{III.8 Musa glossographa}

La musa octava, "glossographa» trata del artificio que consiste en insertar en un poema un verso sacado de otro poema en otra lengua. Como sabemos, fue éste un artificio que no se limitó a la inserción de un único verso, sino que se extendió hasta la formación de los llamados "centones», poemas formados únicamente por versos de otros poetas, como el famoso soneto de Lope «sacado de catorce autores diferentes». Caramuel, sin embargo no habla de los "centones», y se limita a dar dos ejemplos, harto conocidos: uno es el famoso soneto de Garcilaso "Con ansia extrema de mirar qué tiene» que, como es bien sabido, se concluye con un verso tomado de una canción de Petrarca («non esservi passato oltra la gonna») $)^{24}$; el otro ejemplo que trae a colación es de

24. Véase, sobre este soneto, el análisis de Nadine LY, «Mots et regards croisés: Garcilaso, sonnet 22, Pétrarque, chansons $23,37,70$ et 72 et sonnet 38 , Sannazar et les autres...» in 
Góngora, concretamente de la canción compuesta con ocasión de la expedición de la invencible armada en 1588 contra los ingleses («Levanta España tu famosa diestra»). El poeta cordobés echa mano de un soneto "político» de Petrarca ( $V V F$ 136,1), que es una invectiva contra la ciudad de Avińón, sede pontifical, tachada de nueva Babilonia por el poeta toscano, recuperando el verso inicial que es una invocación de un castigo ejemplar de la ciudad corrupta, un verso que Góngora recupera para aplicarlo a los herejes ingleses: "fiamma dal ciel su le tue treccie piova», y que coloca al final de una estancia de su canción ${ }^{25}$. Son interesantes las consideraciones de Caramuel acerca de esta modalidad de bilingüismo, en cuanto insiste en que los versos tomados prestados de otros poetas tienen que ser muy famosos, de otra manera no tienen gracia ( $" M o n u i$, \& moneo Glossemata esse debere aut ab alijs data, aut universis nota, nam alias nullam haberent gratiam»). En cuanto al verso de Góngora, Caramuel lo justifica porque en su opinión la lengua española no es adecuada a las maldiciones, ("exsecrationibus inepta videtur lingua Hispanica, \& ideo solemus alijs uti linguis, ut aliquid durius dicamus»), y es por eso por lo que el poeta cordobés quiso recurrir a otra lengua «ut animi amaritudinem exprimeret, non voluit in lingua materna uti, sed ad peregrinam recurrens». Dicho de otro modo: es otra defensa e ilustración, moral esta vez, de la lengua española, supuestamente inepta para el registro de la imprecación.

\section{III.9 Musa echetica}

La musa novena, «echetica», se concentra en el fenómeno poético de los versos con eco, muy en boga en la poesía barroca, en particular en la pastoril. Aquí también, el eco, que se personifica, contesta en una lengua distinta: es el caso de las dos estancias de una canción entre el pastor Hyacintho y la ninfa Echo, donde el primero se expresa en español, mientras que la segunda le contesta en latín y le expresa su rechazo amoroso: «Por hallarte corrí mill tierras - erras» / No hay yerros Echo que te estimo - et imo / Di, qué se pierde en los amores - mores [...] ¿Con qué podré dejar de amarte? - Marte / ¿Y si la paz me offresce flores? - ores».

Las cuatro últimas musas tienen una relación más tangencial con el plurilingüismo, aunque completan la visión que de este recurso poético tenía Caramuel. Vamos a tratarlas más brevemente.

Mitoyennetés méditerranéennes: Voix croisés, mots croisés, Cahiers du centre interdisciplinaire de méthodologie, Université Michel de Montaigne Bordeaux 3, n. 10, pp. 51-63.

25. La traducción literal sería: "Que la llama del cielo llueva sobre tus trenzas». Henrique Garcés, en su traducción del Canzoniere de 1599 traduce: «Lumbre del cielo en tus hetairas llueva» (en F. Petrarca, Cancionero, intr. y notas de Antonio Prieto, Barcelona, Planeta, 1989, p. 111). 


\section{III.10 Musa parodica}

La décima musa, llamada "Parodica», se refiere a aquellas composiciones poéticas que parafrasean un texto previo, escrito en otra lengua. El resultado es un poema unilingüe, pero que se funda en otro escrito en otra lengua. Caramuel pone como ejemplo una larga paráfrasis latina compuesta por un senador tolosano, Simón Oliva Menillij, publicada en 1642, a partir de la traducción francesa de las Metamorfosis de Ovidio llevada a cabo por Nicolas Renouard en 1651, que iba acompañada de una serie de discursos donde el traductor daba su comentario. Y por lo visto son estos comentarios los que se traducen al latín y constituyen lo propio de la «musa parodica».

\section{III.11 Musa peregrina}

En la musa undécima, "peregrina», Caramuel plantea la posibilidad de aplicar los metros griegos y latinos a todas las lenguas, como queda claro desde el subtítulo: Utrum carmina Hexametra, Pentametra, Iambica, Sapphica, \& $c$. Servatis numeris Gracis Latinisque condi possint in alijs linguis? Su respuesta es positiva, y lo demuestra componiendo hexámetros y sáficos en español e incluso en hebreo (con traducción latina). Esta parte es además muy interesante desde el punto de vista de la historia literaria, puesto que Caramuel parte de las célebres Lecciones solemnes al Polifemo de Góngora, Pindaro andaluz, Príncipe de los Poetas Lyricos de España compuestas por Pellicer en 1630, y discute la denominación de "solemnes» y el apelativo de «Píndaro español». Caramuel le reprocha a Pellicer la incoherencia en la elección de este poeta griego, ya que fue un poeta lírico, mientras que el Polifemo de Góngora es un ejemplo sublime de poesía épica. Caramuel expresa aquí toda su admiración hacia el vate cordobés, autor de un "inventum" "non cultum, sed occultum", lo cual fue la causa de su incomprensión por parte de los espíritus «indigentes», entre los cuales se sitúa Francisco de Quevedo, del cual cita estos dos versos anti-gongorinos: «Es cosa impertinente, / que quien escribió ayer, hoy se comente». Pero lo que Caramuel le discute a Pellicer, en particular, son dos afirmaciones que abren sus Lecciones, a saber: que los versos de arte mayor pueden asimilarse a los sáficos, por un lado, y que éstos fueron un invento de los españoles, que los llamaron "versos de soneto». Se lanza Caramuel en una confutación de estos dos errores, demostrando como el verso de arte mayor se compone de doce sílabas, mientras que el sáfico de once (como vemos, Caramuel asimila la métrica latina y griega a la castellana, hablando de sílabas y no de pies). La segunda parte de su confutación es la que se refiere al origen español de los sáficos (o sea del endecasílabo), y da lugar a una breve historia de este verso, cuya conclusión es algo sorprendente, ya que opta por un origen doble. Para España, según Pellicer el introductor de este verso fue el rey de Portugal don Dionís, de quien dice que floreció hacia 1260, mientras que en Italia lo fue Dante, el cual, siempre según Pellicer, floreció en 1263. Se trata de datos éstos erróneos, puesto que Dante 
en esta fecha aún no había nacido (nació dos años más tarde en 1265), por tanto no podía «florecer» en fecha tan temprana. En cuanto al rey de Portugal, don Dionís, había nacido en 1261, y fue el exacto contemporáneo del poeta florentino. El propio Caramuel se da cuenta de esta incongruencia («fuerunt contemporanei»): sin embargo, comprende el argumento de Pellicer, el cual aprovechaba estos supuestos tres años de ventaja para demostrar el origen hispánico del endecasílabo (no se olvide que en 1630 Portugal formaba parte de la corona de España), y rechazar así los argumentos de los «italianizantes». Es curioso como Caramuel, a pesar de admitir la importancia y el prestigio de la tradición poética italiana, no quiere tomar cartas en el asunto y se limita a una solución salomónica: este verso tuvo su origen en Grecia, por obra de la poetisa Safo, y en España fue introducido por Don Dionís, mientras que en Italia lo fue por Dante. Notamos a la vez el nacionalismo del joven Caramuel ("Primus calamus» significa "primera pluma», o sea que se trata de una obra de juventud) y su postura claramente partidaria de los culteranos. Su conclusión a este capítulo es tajante: en todas las lenguas orientales (y cita ejemplos en hebreo, caldeo, siriaco y árabe) y occidentales (el español, el italiano, el francés, el neerlandés, el alemán, el bohemio, el húngaro, el inglés, el escocés y el irlandés) se pueden componer versos hexámetros, pentámetros, yámbicos, sáficos, anacreónticos, etc. ${ }^{26}$.

\section{III.12 y13 Musa belgica y musa germanica}

Las dos últimas musas se refieren a sendas lenguas extranjeras contemporáneas, que Caramuel conocía por sus estancias en los países correspondientes: el neerlandés de la llamada «musa belgica» y el alemán de la «musa germanica». Se trata de ejemplificar lo que acaba de decir, dando ejemplos de textos poéticos en estas dos lenguas, que él conocía, para demostrar que pueden componerse incluso en estas lenguas, no neolatinas, versos con metros procedentes de las dos tradiciones clásicas, la griega y la latina. Los ejemplos proceden de las principales oraciones cristianas, que Caramuel presenta en la lengua original en forma versificada. Es así como nos topamos con un "Padre Nuestro» en neerlandés en versos heroicos, un «Credo» en versos yámbicos y así varias otras oraciones, cada vez en un metro distinto, acompañadas por la traducción latina. Lo mismo ocurre con el alemán, lengua en la cual nos ofrece el «Padre Nuestro» y otras oraciones traducidas en versos hexámetros y endecasílabos por el famoso naturalista y polígrafo suizo de la primera mitad del siglo XVI, Conrad Gessner. A estos ejemplos añade Caramuel otros sacados de poetas franceses, en particular un fragmento de la segunda Sepmaine de Du Bartas, que cita en francés y luego traduce al alemán, respetando siempre el metro clásico. Termina

26. "His prælibatis principali controversiæ respondeo, afferens etiam in alij linguis Orientalibus, \& Occidentalibus (Hebræe, Chaldæe, Syriaca, Arabica, \& Hispanica, Italica, Gallica, Belgica, Germanica, Bohemica, Hũgarica, Anglica, Scotica, Hibernica, \&c.) posse confici Metra, Hexametra, Pentametra, Iambica, Sapphica, Anacreontica, \&c». 
el libro con un breve apartado dedicado a las lenguas inventadas, que Caramuel titula: «De paraglottis». En particular, transcribe algunas frases sacadas de la lengua de los habitantes de la isla Utopia tal y como aparecen en la célebre obra de Thomas More de 1516, y de las cuales ofrece una traducción latina ${ }^{27}$.

\section{Conclusión}

En este breve repaso de una mínima parcela de la inmensa obra de Juan Caramuel, nos hemos interesado por su peculiar visión del plurilingüismo poético, una temática que de hecho se extiende a varios sectores de su reflexión sobre la técnica poética, tal y como aparece en su extraordinario Primus calamus. En efecto, la presencia de ejemplos en lenguas extranjeras es constante a lo largo de este tratado, tanto en la Rhythmica como en la Metametrica. Sin embargo, en esta última obra, le dedica Caramuel a esta temática un libro entero, cuyo contenido hemos intentado presentar en esta contribución.

Para concluir, quizás valga la pena tratar, brevemente, de mostrar los precedentes que, en ámbito teórico, han podido ofrecer un soporte a este libro, aunque la originalidad de Caramuel es innegable y salta a la vista. Con todo, la reflexión sobre el plurilingüismo poético viene de lejos, y Caramuel está consciente de ello, pues cita a los principales teóricos que le han precedido. Es en particular la variante del bilingüismo sucesivo la que cuenta con los antecedentes más numerosos. De hecho, ya en el primer tratado de métrica de una lengua neolatina, el italiano, o sea la Summa artis rithmici vulgaris dictaminis de Antonio da Tempo, que es de 1332, aparece un apartado dedicado a la composición "De sonettis bilinguibus et eorum forma» ${ }^{28}$. Y no es ninguna casualidad si en las dos principales obras de teoría métrica del Siglo de Oro, la Arte poética española de Juan Díaz Rengifo, publicada en Salamanca en $1592^{29}$, y el Cisne de Apolo de Luis Alfonso de Carballo, de $1602^{30}$, volvemos a encontrar sendos capítulos dedicados a esta clase particular de sonetos titulados respectivamente: «el soneto en dos lenguas» en el primero, $\mathrm{y}$ «de la compostura de dos lenguas y de las ensaladas» en el segundo. Es bien conocida la deuda de Díaz Rengifo con la obra del autor medieval italiano, como es confirmado por el hecho de que el soneto bilingüe italo-francés que cita está sacado precisamente de la obra de

27. Cf. E. Pons, «Les langues imaginaires dans le voyage utopique», in : Revue de littérature comparée, X, 1930, pp. 589-607 ; J. D. Darrett, «T. More and Joseph the Indian», in : Journal of the Royal Asiatic Society, 1962, pp. 18-34. Sobre las lenguas inventadas, véase el interesante libro de Alessandro BAUSANI, Le lingue inventate. Linguaggi artificiali. Linguaggi segreti. Linguaggi universali, Roma, Ubaldini, 1974.

28. Cfr. Antonio da Tempo, Summa artis rithmici vulgaris dictaminis, Patavi, 1332 (ed. mod. a cura di Richard Andrews, Bologna, Commissione per i testi in lingua, 1977).

29. J. Díaz Rengifo, Arte poética española, 1592, ed. facsímil, Madrid, Ministerio de Educación y Ciencia, Dirección general del patrimonio artístico y cultural, 1977, pp. 56-57.

30. Cfr. Luis Alfonso de Carvallo, Cisne de Apolo, 1602, ed. Alberto Porqueras Mayo, Kassel, Reichenberger, 1997, pp. 236-240. 
Antonio da Tempo, como el mismo tratadista español da a entender (sin citar su nombre $)^{31}$.

Acerca de la variedad de las «ensaladas» (valga la imagen vegetal...), se trata de un concepto también antiguo, puesto que las primeras que se cultivaron en el jardín poético español, hasta lo que se nos alcanza, fueron las de Juan del Encina $^{32}$. Rengifo tiene también un capitulillo acerca de esta variante, que define de la siguiente manera: «es una composición en redondillas entre las cuales se mezclan todas las diferencias de metros, no solo españoles, pero de otras lenguas, sin orden de unos a otros, al albedrío del poeta; y según la variedad de las letras, se va mudando la música, y por esso se llama Ensalada, por la mezcla de metros y sonadas que lleva». Y lo ilustra con un ejemplo que añade al final de su repertorio: se trata de una serie de redondillas «A Christo rezien nacido", en castellano, francés, portugués y en vizcaíno. En el Cisne de Apolo, de hecho, encontramos exactamente la misma distinción que hace Caramuel entre plurilingüismo simultáneo y sucesivo, por lo que esta obra ha de considerarse como una de las principales fuentes de inspiración del Primus calamus, máxime cuando sabemos que es ésta una obra de la primera juventud del polígrafo madrileńo. En efecto, Alfonso de Carballo dedica su capítulo XVII a estas dos modalidades: «la compostura en dos lenguas», que define de la siguiente manera: «el artificio de dos lenguas se haze de vocablos que juntamente sean de dos lenguas, como de vocablos que sean Italianos y Franceses, o Españoles, y Latinos, que hagan un mismo sentido, y lo propio signifiquen en una lengua que en otra", mientras que mediante el concepto de «ensalada» expresa la modalidad del plurilingüismo "sucesivo», ofreciendo además el mismo ejemplo que Caramuel, i.e. los dos sonetos de propuesta y respuesta entre Enrique Garcés, el traductor de Petrarca, y el presentado Miguel de Montalvo, a los que aludimos.

Sin embargo, a pesar de estas indudables semejanzas, el tratado del obispo de Vigevano es mucho más complejo y completo, y su visión del plurilingüismo poético, si bien tiene antecedentes, es originalísima y muy personal, al fundarse por un lado en la poética del ars combinatoria y por el otro en la autoridad de las Sagradas Escrituras. Una tentativa, dicho de otro modo, para conciliar los datos de la razón con los de la fe, lo cual confirma la gran modernidad y actualidad de la obra de Juan Caramuel y, por ende, la necesidad de una edición crítica solvente que la dé a conocer.

31. «Exemplo de los primeros puede ser este que hallé en un autor Italiano antiquísimo, en el qual mezcla la lengua Italiana con una de las que se usavan en Francia en su tiempo». Se trata del soneto: «Plus grif mártir del enemic se prent».

32. Véase su importante presencia en el Cancionero musical de los siglos XV y XVI, ed. Asenjo Barbieri, Madrid, 1890 (nn. 337, 342, 429, 432, 436, 445, 455 y 457). Sobre la dimensión musical del bilingüismo poético, cf. F A. Gallo, «Bilinguismo poetico e bilingüismo musicale nel madrigale trecentesco", en L'Ars Nova italiana del Trecento, IV, 1978. 